\title{
Antioxidant Packaging Films Based on Ethylene Vinyl Alcohol Copolymer (EVOH) and Caffeic Acid
}

\author{
Francesca Luzi, Luigi Torre and Debora Puglia *
}

Civil and Environmental Engineering Department, University of Perugia, UdR INSTM, Strada di Pentima 4, 05100 Terni, Italy; francesca.luzi@unipg.it (F.L.); luigi.torre@unipg.it (L.T.)

* Correspondence: debora.puglia@unipg.it; Tel.: +39-0744492916; Fax: +39-0744492950

Academic Editors: Simona Golič Grdadolnik and María del Carmen Garrigós Received: 8 July 2020; Accepted: 28 August 2020; Published: 29 August 2020

\begin{abstract}
The main objective of this research activity was to design and realize active films with tunable food functional properties. In detail, caffeic acid (CA), a polyphenol with high antioxidant effect, was used as active ingredient in poly (vinyl alcohol-co-ethylene) (EVOH) films at $5 \mathrm{wt} . \%$ and $15 \mathrm{wt} . \%$ and successfully realized by means of the solvent casting process. Optical, morphological, thermal and mechanical studies were considered to define the effect of the presence of the CA component on the structural properties of the matrix. In addition, moisture content and antioxidant activity were evaluated, to have clear information on the CA effect in terms of functional characteristics of realized food packaging systems. Results from tensile tests showed increased values for strength and deformation at break in EVOH_CA based films. Results from colorimetric and transparency analysis underlined that the presence of caffeic acid in $\mathrm{EVOH}$ copolymer induces some alterations, whereas the addition of the active ingredient determined a positive radical scavenging activity of the formulations, confirming the possibility of practically using these polymeric systems in the food packaging sector.
\end{abstract}

Keywords: caffeic acid; poly (vinyl alcohol-co-ethylene); antioxidant properties; active packaging

\section{Introduction}

Food packaging comprises a significant part of the packaging industry, so innovations in this sector have been caused and justified by specific applications that require specific properties for the packaging in direct contact with foods. These innovations were motivated mainly by consumer preferences and needs, as well as variations in global trends. The main innovations in packaging, and specifically in the food packaging sector, have been oriented towards the development of ecological systems with active ingredients having antioxidant, antimicrobial and antifungal activities, even being able to reduce, in parallel, environmental pollution and increase shelf-life.

The need to modulate and extend the shelf-life and the freshness of food products is born from the need to increase the storage and transportation time necessary for the containment before sale and consumption [1].

In the last two decades, traditional food packaging was considered unsuitable to guarantee the commercialization and essential shelf-life conditions required by the sector, precisely in the case of fresh or minimally-processed food products [2]. The function of packaging is focused on containing, covering and protection of foods from environmental attacks, such as light radiation, moisture, contaminations and oxidation processes, dangerous for food products susceptible to these external stresses [3]. In order to reduce and obstacle of deterioration and oxidation processes, largely present in delicate/sensitive foods, the presence of inert atmosphere, the use of antioxidant ingredients or the design of a suitable vacuum system packaging technology are the main valid strategies to adopt in the food packaging sector. In this context, the packaging industry is interested in the development of innovative packaging 
and, thus, the food packaging sector is continuously involved in proposing innovative systems, focusing their attention on the realization of smart and active packaging devices [4].

Active packages are based on interactions with the food's environment or the food itself. Active food systems offer the possibility of containing active molecules/principles into packages, allowing the reduction of food additives into the food products, maintaining unchanged quality, safety and the organoleptic characteristics of food products and extending the shelf-life of foodstuffs [5-7]. This research activity proposed the combination of a poly (vinyl alcohol-co-ethylene) (EVOH) polymer matrix and caffeic acid (CA) active ingredient.

$\mathrm{EVOH}$ is a random and semicrystalline copolymer, with high transparency and chemical resistance [8], outstanding interesting barrier properties to gases [9], especially when the content of ethylene in the copolymer is lower than $38 \mathrm{~mol} . \%$ [9]. EVOH has been largely applied in food-packaging applications, being that this sector is categorized by stringent limitations in terms of gases, aroma, water hydrocarbon permeation and chemical resistance. Barrier and mechanical properties of EVOH systems are largely influenced by the presence of moisture in the copolymer chains, in dry conditions this interesting performance is attributed to high inter- and intra-molecular cohesive energy and semi-crystalline polymer structure [10].

Nevertheless, the main negative aspect of EVOH copolymers is their moisture content sensitivity that determines the reduction of thermal, barrier and mechanical properties [11]. In order to modulate the active properties of polymeric matrices or copolymers, natural extracts and essential oils as active ingredients are used and combined with thermoplastic polymers [12-15].

Caffeic acid (CA) (3,4-dihydroxycinnamic) is a phenylpropanoid and hydroxy-cinnamate metabolite, present in plant tissues and also in food sources, including blueberries, apples, cider and coffee drink extracts [16]. Caffeic acid is also present in some medications in popular use, based on propolis [17]. It is used as a carcinogenic inhibitor and it possesses antioxidant and antibacterial activity in vitro, contributing to the prevention of cardiovascular and atherosclerosis diseases $[18,19]$. Natural phenolic antioxidants including caffeic acid have also gained remarkable attention as promising photoprotective agents $[20,21]$ in skin care products, due to their antioxidant activity.

The objective of the present research was the development, production and characterization of EVOH and EVOH_CA thin films for food packaging applications, realized by solvent casting.

In this work, caffeic acid at two different concentrations ( $5 \mathrm{wt} . \%$ and $15 \mathrm{wt} . \%$ ) was used as active agent. The different amounts of CA were selected on the basis of our previous experience in the use of essential oils and natural and active molecules in polymers [22-26]. The systems were deeply characterized by thermal, optical, morphological and mechanical points of view. Finally, functional properties of relevant importance for packaging sector, such as moisture content and antioxidant behaviour, were determined.

\section{Results and Discussion}

\subsection{Caffeic Acid Characterizations}

Figure $1 \mathrm{a}, \mathrm{b}$ show the visual observation (insert chemical structure in a), while Figure $1 \mathrm{c}, \mathrm{d}$ show FESEM images of caffeic acid in the case of pristine powder and after dissolution in 1-propanol/water. CA is a yellowish powder (Figure 1a), FESEM image (Figure 1c) shows that CA is characterized by an irregular cubic crystal structure, similar to flakes, with smooth surfaces [27]. The flakes of caffeic acid have a length distribution ranging between 5 and $50 \mu \mathrm{m}$.

The visual observation and morphological analysis of CA in 1-propanol/water solution are reported in Figure $1 b, d$, respectively. The CA solution is completely transparent (Figure $1 b$ ) maintaining the same colour already observed for the powder, the transparency and solubility are guaranteed by the use of propanol at $70 \% \mathrm{wt}$.

The FESEM image of the caffeic acid solution highlights the procedure selected to obtain the dispersion of active ingredients modified the dimension of initial crystals (Figure 1d). 
The morphological investigation of CA in solution shows that the active ingredient, after the deposition on the silicon and after the drying procedure, appears with 3D polygonal geometric structures, in most cases agglomerations. The morphological appearance of crystals appeared homogenous and smooth.

Powder
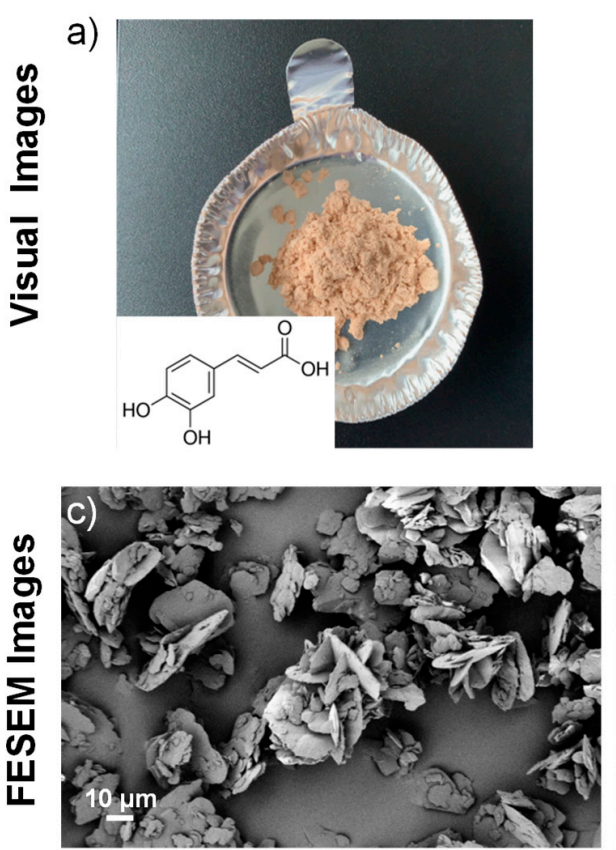

Solution

b)
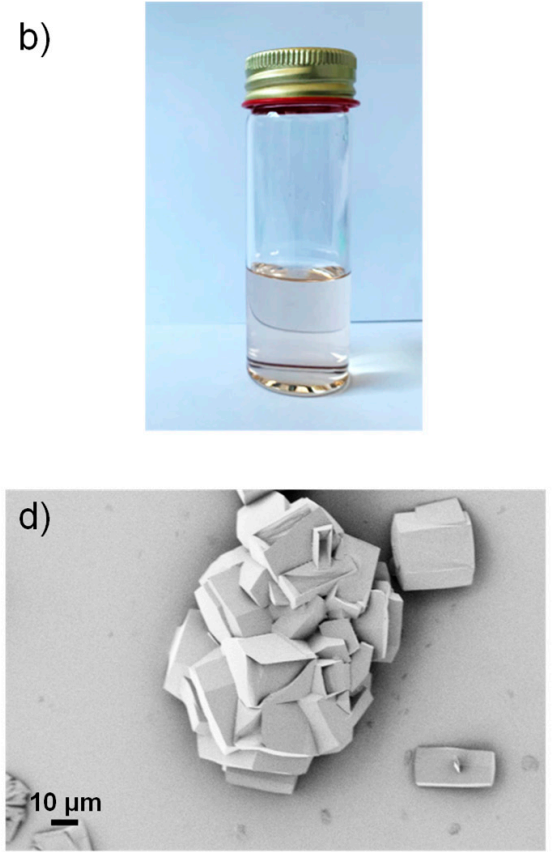

Figure 1. Visual images (chemical structure, see insert of visual image of caffeic acid (CA) powder) of CA powder (a) and solution (b). FESEM images of caffeic acid in powder (c) and after dissolution in 1-propanol/water solution (d).

The thermal stability under inert atmosphere of caffeic acid was determined by thermogravimetric analysis (TGA), Figure 2 shows the residual mass (TG) and the DTG curves of caffeic acid. CA shows a multi-step degradation behaviour [27], similar behaviour has been observed in literature for other active ingredients as hydroxytyrosol [28] and gallic acid [22,29].

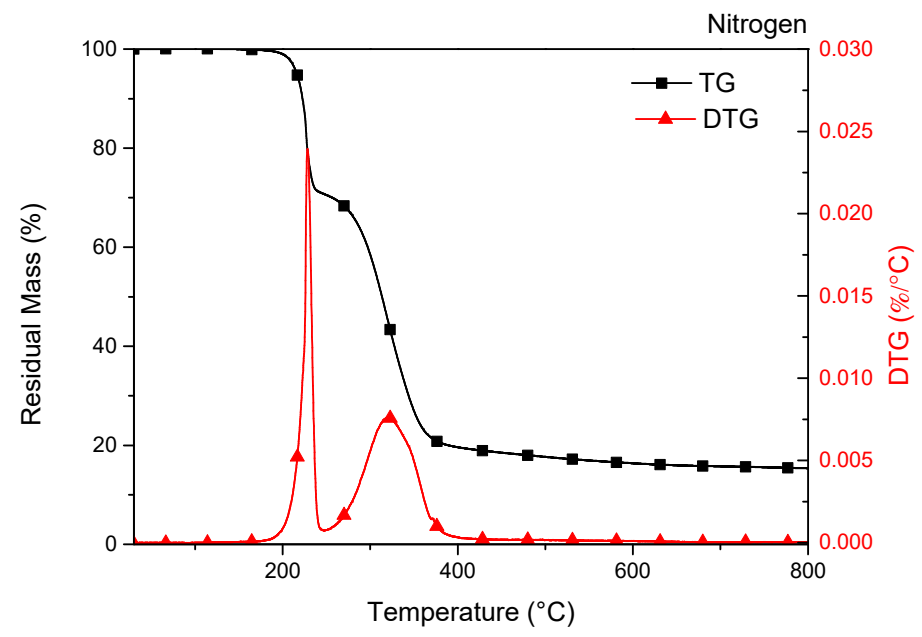

Figure 2. TG (residual mass) and DTG (derivative weight loss) curves of caffeic acid powder under nitrogen atmosphere. 
Profiles of the TG and DTG curves clearly indicate that CA is stable up to $100{ }^{\circ} \mathrm{C}$, while an irregular pattern is visible at higher temperatures, associated with multiple thermal decomposition steps [30]. The caffeic acid starts to decompose $\left(T_{\text {onset }}\right)$ at $140{ }^{\circ} \mathrm{C}$ [31]. The first stage of weight loss (20.9\%), that superimposes melting and degradation of CA [32] was centred at $228.5{ }^{\circ} \mathrm{C}$, while the second decomposition step, characterized by low intensity and centred at $321.4^{\circ} \mathrm{C}$ (weight loss $54.9 \%$ ), can be related to acid decarboxylation [27,32].

\subsection{Transparency, Colorimetric Analysis and FESEM Investigation of EVOH and EVOH_CA Based Systems}

Transparency and colour properties are important characteristics in the food packaging sector. The visual and aesthetic features, in fact, can influence the consumer approval and market success.

Figure 3 shows visual observations (see the insert in the Figure 3) and UV-Vis transmission (a) and absorbance (b) spectra of EVOH and EVOH_CA films. Neat EVOH thin film is a transparent formulation, with a transmittance value of $95 \%$ at a visible wavelength of $700 \mathrm{~nm}$. The transmittance trend is maintained stable up to the wavelength value of $350 \mathrm{~nm}$, a slight reduction was registered from 250 to $350 \mathrm{~nm}$ [33].

The presence of caffeic acid in EVOH films does not modify the transmittance value detected at $700 \mathrm{~nm}$, the transparency of polymeric films combined with active ingredient (EVOH_5CA and EVOH_15CA) is significantly reduced above $425 \mathrm{~nm}$, this behaviour being related to the addition of CA in the polymeric matrix (see Figure 3b). Furthermore, caffeic acid presents two UV-Vis absorption peaks at 291 and $320 \mathrm{~nm}$ [34,35]. The main UV absorbance peak of caffeic acid in EVOH based films is observed at $345 \mathrm{~nm}$ (Figure 3b), in accordance with CA absorbance in the UV region, detectable at 365 and $385 \mathrm{~nm}$, as reported in [36].
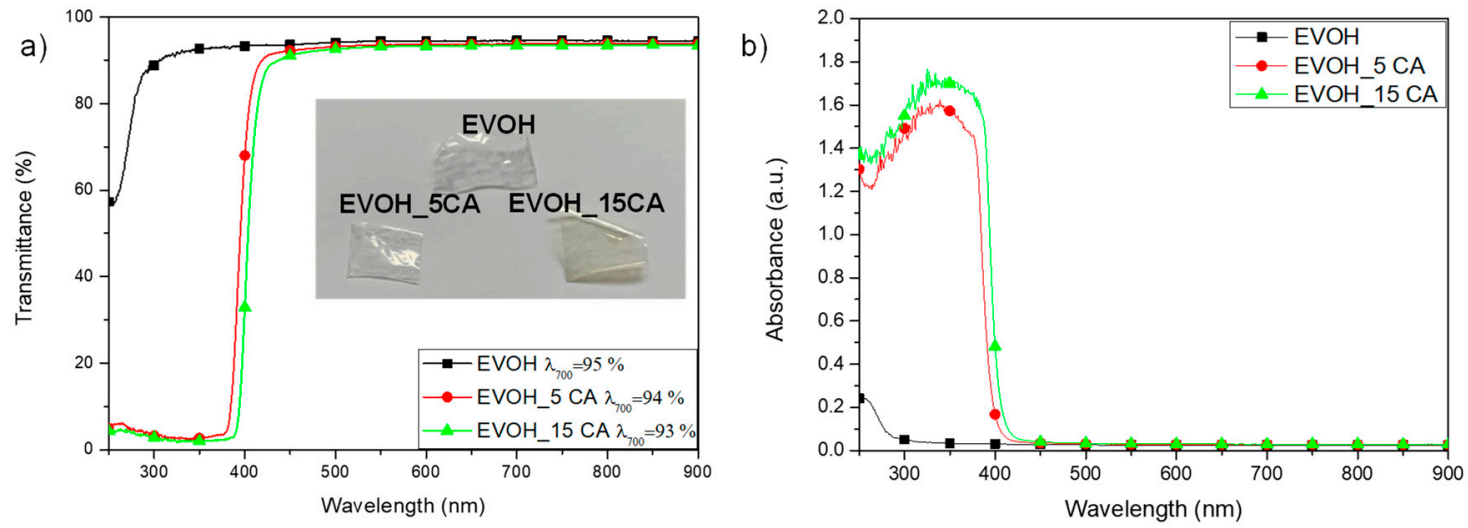

Figure 3. Visual images of the films (insert), transmittance (a) and absorbance (b) UV-Vis spectra of EVOH based formulations.

Colour and gloss values of EVOH and EVOH_CA films are reported in Table 1. The colorimetric and gloss studies have been performed to define the effect of $\mathrm{CA}$ on the aesthetic and optical appearance of $\mathrm{EVOH}$ films. $\mathrm{EVOH}$ is characterized by high lightness value $\left(L^{*}=98.73 \pm 0.16\right)$. Moreover, no significant variations of $L^{*}$ parameter have been registered between neat polymeric film and EVOH_CA (Table 1). All of the samples are homogeneous and transparent (as already observed in the UV-Vis analysis, Figure 3), as the registered lightness values $\left(L^{*}\right)$ have confirmed, analogous reflection has been done for EVOH combined with catechin and gallic acid [37]. The presence of CA induces a colour variation of $a^{*}$ and $b^{*}$ parameters. A reduction of $a^{*}$ was registered increasing the amount of antioxidant agent, as previously observed in literature using CA in fish gelatine [38]. Positive values have been registered in $\mathrm{EVOH}$ film combined with $\mathrm{CA}$ for the $b^{*}$ parameter, indicating a slight deviation towards yellowish, desert sand and brown colour hues. The film appearance and colour effect has been induced by the colour of phenolic ingredient, confirming the results of visual observations and UV-Vis analysis 
(Figure 3, graphs and visual images). The highest $\Delta E^{*}$ value for EVOH films has been obtained for EVOH_15CA film $\left(\Delta E^{*}=3.15 \pm 0.21\right)$.

Table 1. Colour coordinates of EVOH based systems.

\begin{tabular}{cccccc}
\hline Formulations & $\boldsymbol{L}^{*}$ & $\boldsymbol{a}^{*}$ & $\boldsymbol{a}^{*}$ & $\boldsymbol{\Delta} \boldsymbol{E}^{*}$ & Gloss $\left(^{\circ}\right)$ \\
\hline White Control & $99.47 \pm 0.00$ & $-0.08 \pm 0.01$ & $-0.08 \pm 0.01$ & - & $121 \pm 0$ \\
\hline EVOH & $98.73 \pm 0.16$ & $-0.05 \pm 0.00$ & $0.12 \pm 0.00$ & $0.77 \pm 0.15$ & $158 \pm 2$ \\
EVOH_5CA & $98.89 \pm 0.10$ & $-0.25 \pm 0.01$ & $0.43 \pm 0.03$ & $0.80 \pm 0.06$ & $218 \pm 3$ \\
EVOH_15CA & $98.45 \pm 0.28$ & $-1.06 \pm 0.03$ & $2.73 \pm 0.16$ & $3.15 \pm 0.21$ & $188 \pm 5$ \\
\hline
\end{tabular}

The morphology of EVOH based films was investigated by FESEM. Figure 4 shows the microstructure of fractured cross sections of EVOH based films at two different magnifications. The FESEM analysis was carried out to investigate and evaluate the effect, on microstructure, of the phenolic agent.
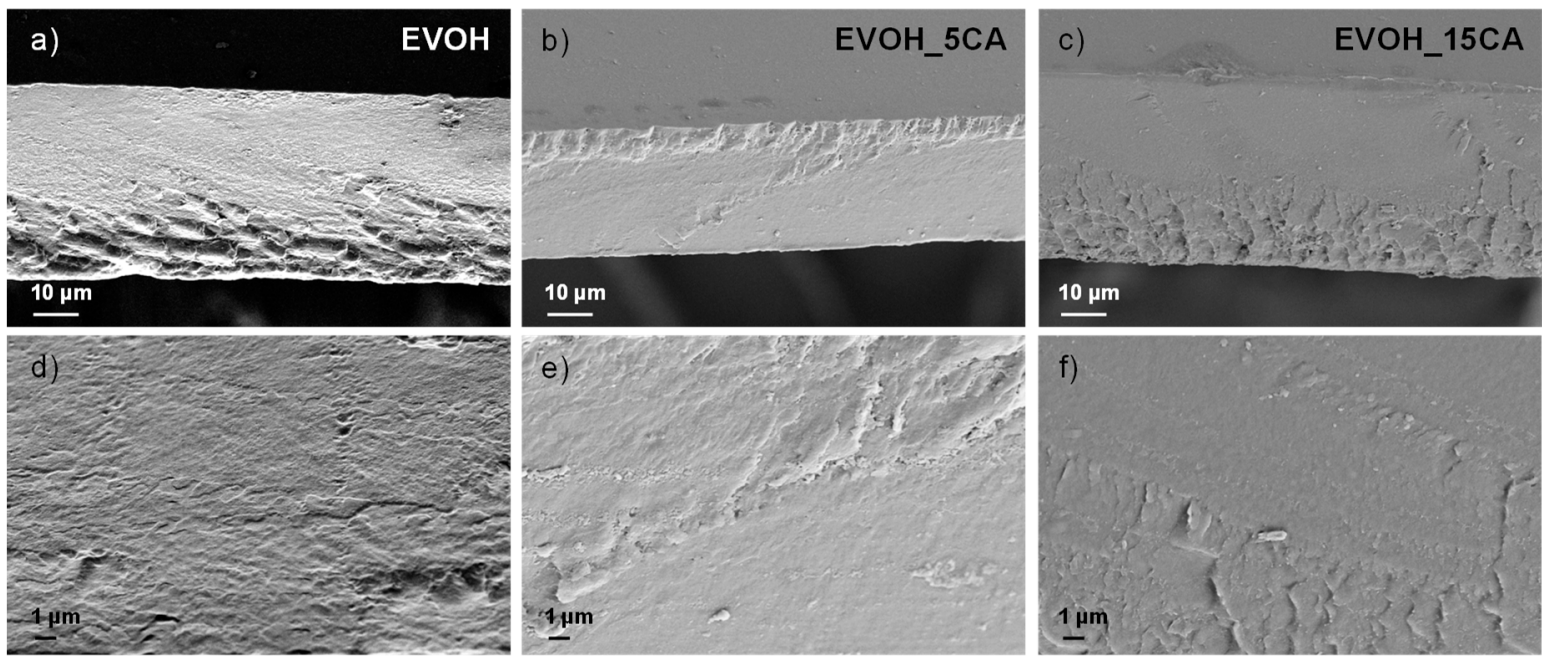

Figure 4. FESEM investigation of fractured surfaces of EVOH based formulations at two different magnifications: $\mathrm{EVOH}(\mathbf{a}, \mathbf{d}), \mathrm{EVOH} \_5 \mathrm{CA}(\mathbf{b}, \mathbf{e})$ and EVOH_15CA $(\mathbf{c}, \mathbf{f})$.

EVOH films show an uniform, homogenous and smooth fractured surface (Figure 4a,d) [39], normally obtained for thermoplastic semi-crystalline and well processed polymeric matrices and copolymers [26]. This characteristic highlights the good film-forming processability and properties of EVOH films during the selected process. The presence of CA (5 and $15 \mathrm{wt} \%$ ) in cast based films does not induce alterations in terms of uniformity and homogeneity on the fractured surfaces of EVOH_CA films (Figure 4). The homogenous dispersion of $\mathrm{CA}$ in $\mathrm{EVOH}$ films is also related to the high solubility of CA in the 1-propanol/water solution that has also been demonstrated by the FESEM analysis of the CA ingredient (Figure 1d).

\subsection{Thermal Characterizations of EVOH and EVOH_CA Based Systems}

In order to determine the effect of $\mathrm{CA}$ presence and content on final thermal characteristics of EVOH realized films, thermogravimetric analysis (TGA) and differential scanning calorimetry (DSC) under inert atmosphere of EVOH based formulations produced by solvent casting have been considered. Figure 5a shows the derivative curves (DTG). The DTG curves of neat EVOH and EVOH_CA films show the presence of a multi-step degradation behaviour (Figure 5a). The first peak centred at low temperature (about $110-120^{\circ} \mathrm{C}$ ) corresponds to the evaporation of residual solvent (1-propanol/water) [40]. 
a)

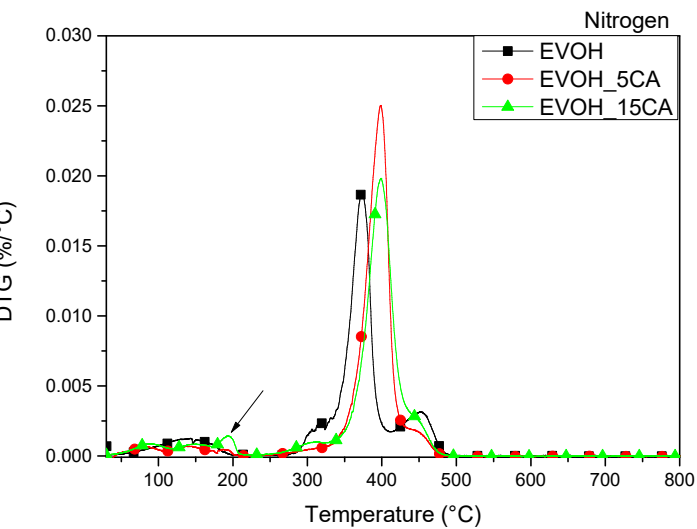

c)

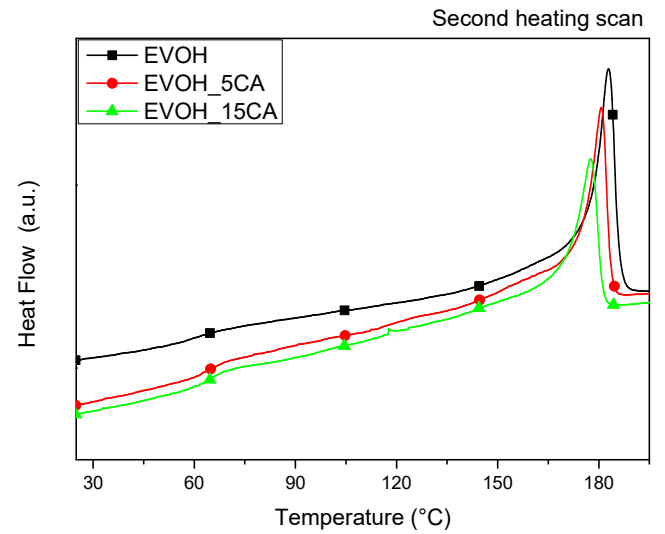

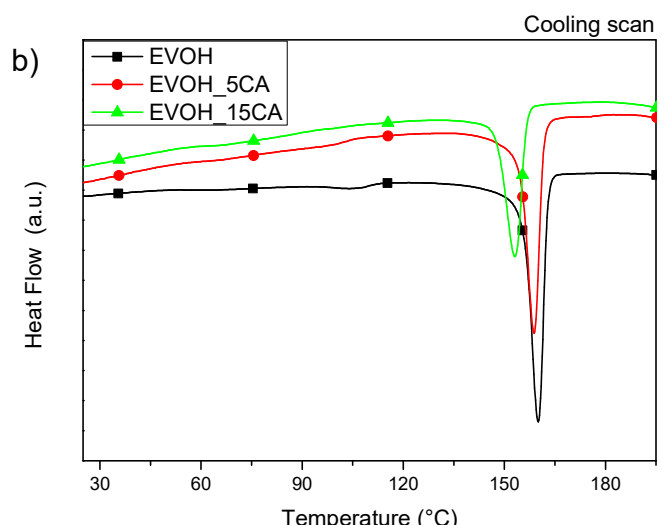

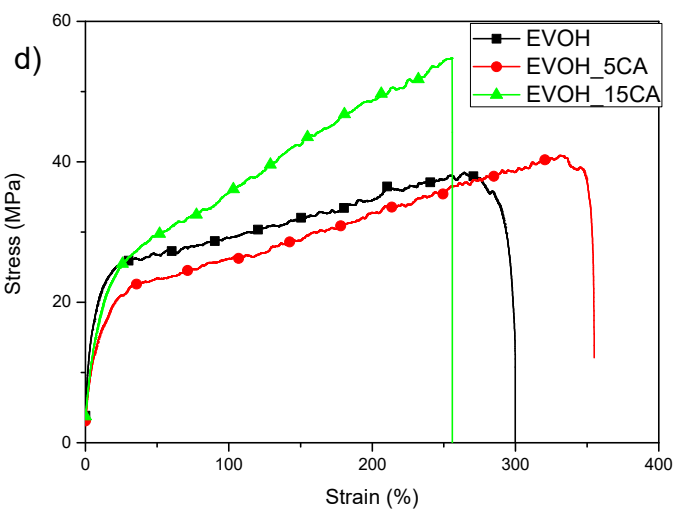

Figure 5. Derivative curves (DTG) (a), DSC thermograms cooling (b) and second heating scans (c) and stress-strain curves (d) of EVOH based formulations.

The EVOH film shows two main degradation steps, the first at $373{ }^{\circ} \mathrm{C}$, attributed to the major component fraction, poly (vinyl alcohol) [41,42]. The second one at higher temperature, at approximately $450^{\circ} \mathrm{C}$, could be ascribed to the ethylene component [42]. EVOH_CA based films show a peak centred at $194{ }^{\circ} \mathrm{C}$, the intensity increased with increasing content of CA in the copolymer matrix (see the arrow Figure 5a) and could essentially be associated with the thermal degradation of caffeic acid.

As reported above, CA starts the degradation step $\left(T_{\text {onset }}\right)$ at $140{ }^{\circ} \mathrm{C}[31]$, while the first and main weight loss of active agent is centred at $228.5^{\circ} \mathrm{C}$ [27,32] (Figure 2).

In the presence of $\mathrm{CA}$, the thermal resistance of both formulations is enhanced, a shift of the main degradation temperature $\left(\mathrm{T}_{\text {main peak }}\right)$ at higher value is registered $\left(\mathrm{T}_{\text {main peak }} \mathrm{EVOH}=373^{\circ} \mathrm{C}, \mathrm{T}_{\text {main peak }}\right.$ $\left.\mathrm{EVOH} \_5 \mathrm{CA}=398^{\circ} \mathrm{C}, \mathrm{T}_{\text {main peak }} \mathrm{EVOH} \_15 \mathrm{CA}=399^{\circ} \mathrm{C}\right)$. Observing the thermal profile of the main degradation step of EVOH_CA based films, it is possible to highlight that all the profile peaks are shifted at higher temperatures of about $25^{\circ} \mathrm{C}$. A similar trend has already been detected in previous works where EVOH was combined with gallic acid, umbelliferone and green tea extract [41] and combining other polyphenols in thermoplastic polymeric matrices [26,28]. Thermal properties of EVOH formulations have also been analysed by DSC analysis in order to evaluate the effect of caffeic acid presence and quantity on the crystallization and melting phenomena of the copolymer matrix. The DSC data related to the glass transition, crystallization and melting phenomena determined during the cooling and the second heating scan are summarized in Table 2. The DSC thermograms of the cooling scan and the second heating scan of EVOH based films are reported in Figures $5 b$ and $5 c$, respectively. 
Table 2. Mechanical properties of EVOH based systems.

\begin{tabular}{|c|c|c|c|c|c|c|}
\hline \multirow{2}{*}{ Formulations } & \multicolumn{6}{|c|}{ Cooling Scan } \\
\hline & $T_{g}\left({ }^{\circ} \mathrm{C}\right)$ & $\Delta H^{\prime}{ }_{c}\left(\mathrm{~J} \mathrm{~g}^{-1}\right)$ & $T_{c}^{\prime}\left({ }^{\circ} \mathrm{C}\right)$ & $\Delta H^{\prime \prime}{ }_{c}\left(\mathrm{~J} \mathrm{~g}^{-1}\right)$ & $T^{\prime \prime}{ }_{c}\left({ }^{\circ} \mathrm{C}\right)$ & $X_{c}(\%)$ \\
\hline EVOH & $61.0 \pm 0.7$ & $2.2 \pm 0.2$ & $104.9 \pm 0.4$ & $71.8 \pm 0.4$ & $159.9 \pm 0.2$ & $36.6 \pm 0.3$ \\
\hline EVOH_5CA & $60.2 \pm 1.0$ & $0.9 \pm 0.2$ & $98.5 \pm 1.1$ & $59.3 \pm 3.3$ & $158.2 \pm 0.8$ & $31.3 \pm 1.8$ \\
\hline EVOH_15CA & $60.2 \pm 0.4$ & - & - & $48.3 \pm 1.4$ & $153.6 \pm 0.6$ & $28.1 \pm 0.8$ \\
\hline \multirow{2}{*}{ Formulations } & \multicolumn{6}{|c|}{ Second Heating Scan } \\
\hline & $T_{g}\left({ }^{\circ} \mathrm{C}\right)$ & \multicolumn{2}{|c|}{$\Delta H_{m}\left(\mathrm{~J} \mathrm{~g}^{-1}\right)$} & $T_{m}\left({ }^{\circ} \mathrm{C}\right)$ & \multicolumn{2}{|r|}{$X_{m}(\%)$} \\
\hline EVOH & $64.6 \pm 0.3$ & \multicolumn{2}{|c|}{$83.2 \pm 0.1$} & $182.9 \pm 0.1$ & \multicolumn{2}{|r|}{$41.1 \pm 0.1$} \\
\hline EVOH_5CA & $66.0 \pm 2.3$ & \multicolumn{2}{|c|}{$68.3 \pm 0.3$} & $178.7 \pm 2.7$ & \multicolumn{2}{|r|}{$35.3 \pm 0.1$} \\
\hline EVOH_15CA & $66.2 \pm 2.1$ & \multicolumn{2}{|c|}{$55.7 \pm 0.8$} & $173.7 \pm 1.5$ & \multicolumn{2}{|r|}{$32.4 \pm 0.5$} \\
\hline
\end{tabular}

No evident variations have been found in terms of glass transition temperature at cooling and second heating scan adding caffeic acid in EVOH based systems.

Results obtained from the cooling scan highlight the presence of two crystallizations peaks, the first placed at low temperature, approximately at $105^{\circ} \mathrm{C}$ for neat $\mathrm{EVOH}$, and the second one centred at a higher temperature (about $160^{\circ} \mathrm{C}$ ) (Table 2 and Figure $5 \mathrm{~b}$ ); consequently the crystallization degrees are reduced, the lower value of $X_{c}$ has been found for EVOH_15CA $\left(X_{c}=(28.1 \pm 0.8) \%\right)$ with respect to the value obtained for $\mathrm{EVOH}\left(X_{c}=(36.6 \pm 0.3) \%\right)$. Furthermore, during the second heating scan, the presence of caffeic acid induced a general decrease of the $T_{m}$ and the $\Delta H_{m}$ values, this trend is confirmed using different contents of CA [40]. As observed before, the reduction of $\Delta H_{m}$ also determined a decrease of $X_{m}$. As reported in the paper by Vannini et al. [43], the addition of low-molecular weight additives in $\mathrm{EVOH}$ is a possible strategy to pursue in order to create hydrogen or covalent bonds with the $\mathrm{OH}$ groups of the EVOH main chains, thus influencing the crystallization process.

\subsection{Mechanical Properties of EVOH and EVOH_CA Formulations}

The presence and the effect of $\mathrm{CA}$ in the $\mathrm{EVOH}$ matrix was investigated in terms of mechanical properties. Mechanical data for EVOH and EVOH_CA films were determined from stress-strain curves obtained carrying out tensile analyses at room temperature (RT). The stress-strain curves of different formulations are reported in Figure 5d, while the results are summarized in Table 3.

Table 3. Mechanical properties of EVOH based films.

\begin{tabular}{cccc}
\hline Formulations & $\boldsymbol{\sigma}_{\mathbf{b}}(\mathbf{M P a})$ & $\boldsymbol{\varepsilon}_{\mathbf{b}}(\mathbf{\%})$ & E $_{\text {Young }}(\mathbf{M P a})$ \\
\hline EVOH & $45 \pm 4$ & $265 \pm 28$ & $440 \pm 65$ \\
EVOH_5CA & $41 \pm 3$ & $310 \pm 26$ & $232 \pm 11$ \\
EVOH_15CA & $58 \pm 4$ & $263 \pm 11$ & $207 \pm 11$ \\
\hline
\end{tabular}

The presence of CA added at two different concentrations determined modulation and variations of mechanical performance with respect to neat EVOH film (Figure $5 \mathrm{~d}$ ). In detail, the presence of the phenolic ingredient in EVOH film determined an improvement of strength at break $\left(\sigma_{\mathrm{b}}\right)$. Focusing on the elongation at break and on Young's modulus values obtained for all EVOH based formulations, it is relevant to observe that the films show an evident ductile behaviour (see Figure $5 \mathrm{~d}$ and Table 3 ). In fact, strain at break $\left(\varepsilon_{\mathrm{b}}\right)$ increases in EVOH_5CA, while a reduction of $\varepsilon_{\mathrm{b}}$ was observed in EVOH_15CA with respect to the value registered for neat EVOH. In fact, $\varepsilon_{\mathrm{b}}$ increases in $\mathrm{EVOH} \_5 \mathrm{CA}$, while a reduction of strain at break was observed in $\mathrm{EVOH}_{-} 15 \mathrm{CA}$. The presence of CA is able to modulate the mechanical performance in the elastic and plastic zones, in relation to the quantity of active ingredient. Adding $5 \mathrm{wt} \%$ and $15 \mathrm{wt} \%$ of phenolic ingredient a clear reduction of Young's modulus was observed $\left(\mathrm{E}_{\text {Young }}(\mathrm{EVOH})=(440 \pm 65) \mathrm{MPa}, \mathrm{E}_{\text {Young }}\left(\mathrm{EVOH}_{-} 5 \mathrm{CA}\right)=(232 \pm 11) \mathrm{MPa}, \mathrm{E}_{\text {Young }}\left(\mathrm{EVOH} \_15 \mathrm{CA}\right)=(207 \pm 11)\right.$ $\mathrm{MPa})$, similar behaviour was observed in literature combining gallic acid and umbelliferone in EVOH 
based systems [22]. Concluding, EVOH_5CA shows the best mechanical response to tensile stress in terms of elastic and plastic behaviour.

\subsection{Antiradical Activity and Moisture Content of EVOH_CA Based Systems}

Antiradical activity and moisture content characteristics are considered the main important properties required by polymeric devices applied in the food packaging sector and used in direct contact with food products. The addition of active compounds into polymeric systems determines the antioxidant action. The antioxidant effect of polymeric materials is based on a migration process, into the foodstuff, of active molecules incorporated in polymeric packaging [6]. The continued need for food products with long shelf lives promoted the development of active food packaging systems, this demand was satisfied using active polyphenol molecules in packaging. The antioxidant properties of produced films were determined by the evaluation of the scavenging activity of methanol migration extracts against the DPPH radical. The test represents an indirect method applied to estimate the antioxidant effect of CA on food products. Table 4 and Figure $6 a, b$ summarize the antioxidant effect of migrating substances in methanol for $24 \mathrm{~h}$ for polymeric films. Neat EVOH was selected as control. In more detail, Figure 6a shows the monitoring of the absorbance band at $517 \mathrm{~nm}$ for migrating substances from EVOH and EVOH_CA based formulations immersed directly in the methanol solution for $24 \mathrm{~h}$, while Figure $6 \mathrm{~b}$ shows the colour variation of the DPPH methanol solution. CA, and in general the polyphenols, intercept and reduce the effect of the free radical chain of oxidation by donating hydrogen from the phenolic hydroxyl groups. The active process induces the formation of a stable end product, which does not start or extend the lipid oxidation induced in the presence of oxygen and lipids [44].

Table 4. Radical scavenging activity (RSA) of EVOH based systems.

\begin{tabular}{cc}
\hline Formulations & Radical Scavenging Activity, RSA (\%) \\
\hline EVOH & 0 \\
EVOH_5CA & $91.1 \pm 0.5$ \\
EVOH_15CA & $93.6 \pm 0.4$ \\
\hline
\end{tabular}
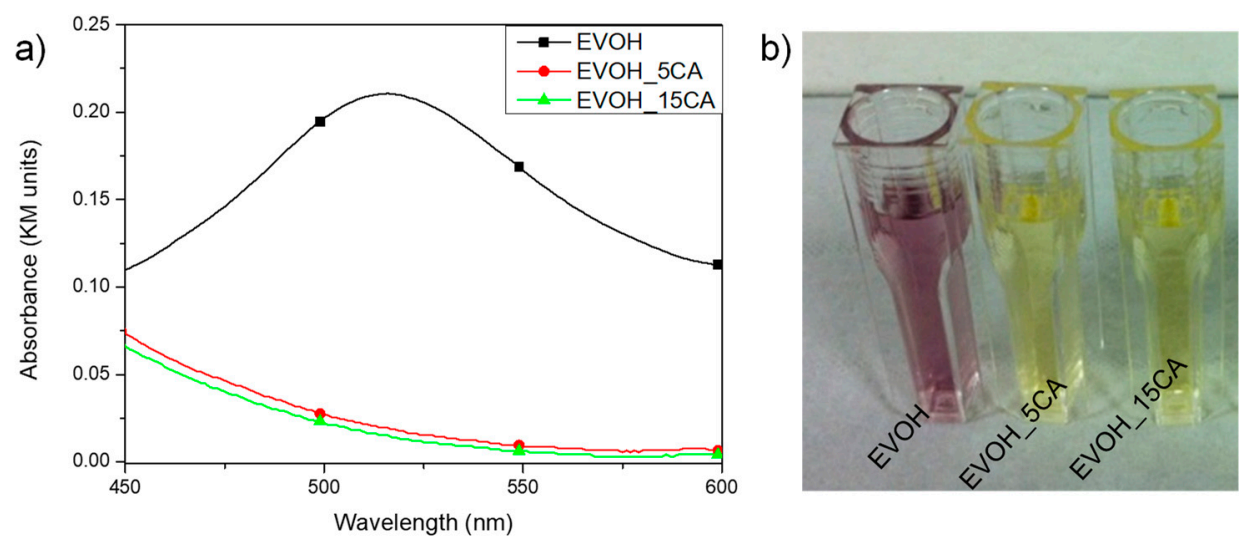

Figure 6. Antioxidant activities of migrating substances for EVOH and EVOH_CA based formulations immersed directly in the methanol solution for $24 \mathrm{~h}$ : monitoring of the absorbance band at $517 \mathrm{~nm}$ (a) and colour variation of the DPPH methanol solution (b).

The incorporation of CA guarantees a clear antiradical scavenging activity (see Figure 6a,b and Table 4), as also confirmed in the literature [17,45]. The higher RSA\% value was registered using a low content of active ingredient (RSA $(\%):$ EVOH_5 CA $=(91.1 \pm 0.5) \%)$. Nevertheless, the addition of increasing content of $\mathrm{CA}(15 \mathrm{wt} \%)$ in the $\mathrm{EVOH}$ film does not improve significantly the antioxidant response $\left(\mathrm{RSA}(\%): \mathrm{EVOH} \_15 \mathrm{CA}=(93.6 \pm 0.4) \%\right)$. The phenomenon is due to the presence of CA, characterized by high antioxidant ability $[17,45]$. Table 5 shows the moisture content (MC) values 
of $\mathrm{EVOH}$ based samples, determined at different times, after 1 and 5 storage weeks at $53 \% \mathrm{RH}$ and $25{ }^{\circ} \mathrm{C}$. The evaluation of $\mathrm{MC}$ and the ability of polymeric films to absorb the $\mathrm{H}_{2} \mathrm{O}$ in the form of moisture represent a crucial focus in food packaging applications, specially using edible films. Pastor and co-authors proposed the development and the characterization of edible films based on hydroxypropylmethylcellulose combined with different concentrations of an ethanolic extract of propolis [46]. In this research, the authors studied how the moisture content influenced the mechanical, water barrier and optical properties of the matrix [46].

Table 5. Moisture content (MC) of EVOH based systems.

\begin{tabular}{ccc}
\hline Formulations & MC (\%) @ 1 Week & MC (\%) @ 5 Week \\
\hline EVOH & $1.49 \pm 0.10$ & $1.53 \pm 0.14$ \\
EVOH_5CA & $1.97 \pm 0.10$ & $1.98 \pm 0.05$ \\
EVOH_15CA & $1.98 \pm 0.09$ & $2.01 \pm 0.08$ \\
\hline
\end{tabular}

The test gives the possibility of estimating the moisture content in different environmental conditions (temperature and relative humidity). The variation/increase of moisture content causes a significant loss in terms of mechanical, thermal and barrier properties at high relative humidity. The absorbed moisture determines an increase of the copolymer free volume in the polymeric chains [10]. The moisture content of the EVOH film was $(1.49 \pm 0.10) \%$ and $(1.53 \pm 0.14) \%$ after 1 and 5 weeks, respectively. The equilibrium was achieved in the first week of storage in these specific conditions $[22,33,47]$. The presence of caffeic acid at two different concentrations in the EVOH film induces a slight increase of absorbed moisture, the equilibrium is guaranteed in the first week of storage. No evident variations of $\mathrm{MC} \%$ were observed comparing the data obtained from EVOH_5CA and EVOH_15CA at different times. The slight increase of $\mathrm{MC} \%$ in EVOH_CA based films is also related to the lower crystallinity degrees $\left(X_{c}\right.$ and $\left.X_{m}\right)$ registered from DSC data (Table 3).

\section{Materials and Methods}

\subsection{Materials}

Poly (vinyl alcohol-co-ethylene) with $32 \mathrm{~mol} \%$ ethylene content (EVOH 32) (density: $1.19 \mathrm{~g} / \mathrm{mL}$ at $25^{\circ} \mathrm{C}$, melt index: $\left.3.8 \mathrm{~g} / 10 \mathrm{~min}\left(210^{\circ} \mathrm{C}\right)\right)$, 1-propanol reagent, $\geq 99.5 \%$, caffeic acid $(\mathrm{CA})\left(\mathrm{C}_{9} \mathrm{H}_{8} \mathrm{O}_{4}\right.$, with $98.0 \%$ of purity, average, average $M_{w}=180.16 \mathrm{~g} \mathrm{~mol}^{-1}$ ) were obtained from Sigma-Aldrich (Milan, Italy).

\subsection{Characterization of Caffeic Acid}

The thermal stability of caffeic acid was determined by using thermogravimetric analysis (TGA, Seiko Exstar 6300, Tokyo, Japan) under nitrogen flow (200 mL min $\left.{ }^{-1}\right)$. Heating scans were performed from 30 to $800{ }^{\circ} \mathrm{C}$ at $10{ }^{\circ} \mathrm{C} \mathrm{min}^{-1}$ and three repetitions of the test have been considered.

The microstructure appearance of CA in powder state and after dissolution in 1-propanol/water solution (10 wt/v.\%) was analysed by field emission scanning electron microscope (FESEM, Supra 25-Zeiss). The powder was deposited on conductive adhesive, gold sputtered and analysed, while a few drops of the CA suspension (1-propanol/water (70:30 wt/wt)) were cast on a silicon substrate, dried at room temperature and visualized after gold sputtering. A magnetic stirring at room temperature for $1 \mathrm{~h}$ and a sonication bath treatment (Ultrasonic bath-mod.AC-5, EMMEGI, Milano, Italy) for 1 additional hour were applied in order to obtain a uniform dispersion of CA in the 1-propanol based solution.

\subsection{Production of EVOH and EVOH_CA Systems}

EVOH and EVOH_CA based films with 5 and 15 wt.\% of caffeic acid (respectively, EVOH_5CA and EVOH_15CA) were prepared by solvent casting method following the procedure reported in 
literature [48]. EVOH was initially dissolved in 1-propanol/water (70:30 wt/wt.\%) in the ratio 8:92 (wt/wt.\%) under magnetic stirring at $100^{\circ} \mathrm{C}$ for $2 \mathrm{~h}$. EVOH_CA systems were obtained by mixing EVOH solution with a specific amount of the CA previously dispersed in 1-propanol/water. CA dispersion was obtained by applying a two-step procedure: firstly, the CA was dispersed under magnetic stirring in 1-propanol/water solution (10 wt/v.\%) for $1 \mathrm{~h}$ at room temperature (RT), after that a bath sonication treatment (Ultrasonic bath-mod.AC-5, EMMEGI, Italy) was applied for $1 \mathrm{~h}$ at RT. The EVOH solution was cooled down to approximately $60^{\circ} \mathrm{C}$ and then mixed with the CA solution by magnetic stirring for $1 \mathrm{~h}$ at RT. Finally, EVOH solutions were cast in a Teflon Petri dish and dried in an oven at $60^{\circ} \mathrm{C}$ for $3 \mathrm{~h}$. The films ( $140 \mathrm{~mm}$ diameter and $50-70 \mu \mathrm{m}$ thick) were stored and equilibrated for 2 days in a desiccator by using silica salts, after processing and before characterizations [49].

\subsection{Characterization of EVOH_CA Based Films}

\subsubsection{Transparency, Colorimetric Analysis and FESEM Investigation}

The transparency of different EVOH films produced by using solvent casting was tested by UV-Vis spectroscopy in the range $250-900 \mathrm{~nm}$ by using a Perkin Elmer Lambda 35.

The fractured surfaces of EVOH and EVOH_CA films were analysed by FESEM (Supra 25-Zeiss, Oberkochen, Germany) after gold sputtering and by using an accelerating voltage of $5 \mathrm{kV}$. The different $\mathrm{EVOH}$ formulations were previously freeze-cut in liquid nitrogen, gold-coated with an Agar automatic sputter coater and then characterized.

CIELAB colour space parameters of EVOH produced systems were determined by using a spectrophotometer (CM-2300d Konica Minolta, Tokyo, Japan). The data were examined by using the SCI 10/D65 method, however CIELAB colour, as proposed by the Commission Internationale de 1'Éclairage (CIE 1995), were used. The polymeric films were positioned on a white standard substrate and $L^{*}, a^{*}$ and $b^{*}$ parameters were determined. Samples were examined in triplicate, and three measurements were obtained at random locations on each of the produced films. The total colour difference $\Delta E^{*}$ between EVOH based systems was obtained as indicated in Equation (1):

$$
\Delta E^{*}=\sqrt{\left(\Delta L^{*}\right)^{2}+\left(\Delta a^{*}\right)^{2}+\left(\Delta b^{*}\right)^{2}}
$$

Gloss value was also determined by using the SCI 10/D65.

\subsubsection{Thermal Characterizations}

Thermal characterization of the EVOH was performed by thermogravimetric measurements (TGA) and by differential scanning calorimetry (DSC). Thermogravimetric measurements were carried out by using a Seiko Exstar 6300 . Heating scans from 30 to $600{ }^{\circ} \mathrm{C}$ at $10^{\circ} \mathrm{C} \mathrm{min}{ }^{-1}$ under nitrogen flow $\left(200 \mathrm{~mL} \mathrm{~min}^{-1}\right)$ were performed for each sample.

Differential scanning calorimetric measurements were performed on a TA Instruments DSC Q200 (TA Instruments Inc., New Castle, DE, USA) under nitrogen flow in the range from -25 to $210{ }^{\circ} \mathrm{C}$ at $10{ }^{\circ} \mathrm{C} \mathrm{min}-1$, carrying out two heating and one cooling scans. The glass transition temperature $\left(T_{g}\right)$ was investigated during cooling and second heating scan; crystallization temperature and enthalpy ( $T_{c}$ and $\Delta H_{c}$ ) were determined from the cooling scan, whereas the melting temperature and enthalpy ( $T_{m}$ and $\Delta H_{m}$ ) were determined from the second heating scan.

The crystallinity degree was evaluated according to Equation (2):

$$
\chi=\frac{1}{\left(1-m_{f}\right)}\left[\frac{\Delta H}{\Delta H_{0}}\right] \times 100
$$

where $\Delta \mathrm{H}$ is the enthalpy for melting or crystallization; $\Delta \mathrm{H}_{0}$ is melting enthalpy for a $100 \%$ crystalline $\mathrm{EVOH}$ sample and $\left(1-m_{f}\right)$ is the weight fraction of $\mathrm{EVOH}$ in the sample. 
The melting enthalpy at 100\% of EVOH was calculated according to Equation (3) [50]:

$$
\Delta H_{0}=\alpha \Delta H_{0}^{P V A}+\beta \Delta H_{0}^{P E}
$$

where $\Delta \mathrm{H}_{0}{ }^{\mathrm{PVA}}$ is enthalpy of melting for a $100 \%$ crystalline poly(vinyl alcohol) (PVA), taken as $161.1 \mathrm{~J} \mathrm{~g}^{-1}$ [51], while $\Delta \mathrm{H}_{0}{ }^{\mathrm{PE}}$ is enthalpy of melting for a $100 \%$ crystalline of polyethylene (PE) taken as $290.0 \mathrm{~J} \mathrm{~g}^{-1}$ [50] $\alpha$ and $\beta$ are the weight fractions of vinyl alcohol $(\alpha=0.68)$ and ethylene $(\beta=0.32)$ in EVOH. $\Delta \mathrm{H}_{0}$ melting enthalpy for a $100 \%$ crystalline $\mathrm{EVOH}$ is taken as $202.4 \mathrm{~J} \mathrm{~g}^{-1}[22,33]$.

\subsubsection{Mechanical Characterization}

Tensile tests of neat EVOH and EVOH_CA systems were carried out to estimate the effect of caffeic acid addition on the mechanical performance of the polymeric matrix. The tests were performed by using a universal test machine (LR30KPlus, Lloyd Instruments Ltd, Bognor Regis, UK) according to UNI ISO 527 rectangular probes about $80 \mu \mathrm{m}$ thick, a crosshead displacement rate of $5 \mathrm{~mm} \mathrm{~min}^{-1}$ was used. Young's modulus ( $\mathrm{E}_{\text {Young }}$ ), the tensile strength $\left(\sigma_{\mathrm{b}}\right)$ and elongation at break $\left(\varepsilon_{\mathfrak{b}}\right)$ were determined from the resulting stress-strain curves. The tests were performed at room temperature and at least five samples for each formulation were analysed.

\subsubsection{Antiradical Activity}

The radical scavenging activity of different films was verified by using a spectroscopic technique according to the method planned in literature [22,52]. The different formulations $(0.1 \mathrm{~g})$ were reduced into small dimensions and immersed in $2 \mathrm{~mL}$ of methanol for $24 \mathrm{~h}$ at RT. An amount of methanol extract $(1 \mathrm{~mL})$ was mixed with $1 \mathrm{~mL}$ of DPPH in methanol $\left(50 \mathrm{mg} \mathrm{L}^{-1}\right)$. The methanolic mixture was maintained at RT in the dark for $60 \mathrm{~min}$. The absorbance was measured at $517 \mathrm{~nm}$ using a UV spectrometer (Lambda 35). The DPPH obtained solution of methanol extracted from neat EVOH formulation was used as control. DPPH radical scavenging activity (RSA) was determined according to Equation (4):

$$
R S A(\%)=\frac{A_{\text {Control }}-A_{\text {Sample }}}{A_{\text {Control }}} * 100
$$

where $A_{\text {sample }}$ is the absorbance of sample and $A_{\text {control }}$ is the absorbance of the control.

\subsubsection{Moisture Content}

The moisture content (MC) of EVOH based formulations was calculated at room temperature and $53 \% \mathrm{RH}$. First of all, EVOH and EVOH_CA films were equilibrated in a vacuum oven at $40{ }^{\circ} \mathrm{C}$ for $72 \mathrm{~h}$ (drying step), after this step the films were placed in desiccators containing $\mathrm{Mg}\left(\mathrm{NO}_{3}\right)_{2}$ salts until the constant weight was reached. Three replicates for each formulation for 1 and 5 weeks were evaluated. MC was determined according to the Equation (5):

$$
M C(\%)=\frac{W_{\text {Final }}-W_{\text {Initial }}}{W_{\text {Final }}} * 100
$$

where $W_{\text {Final }}$ is the weight of different materials after 1 or 5 weeks at $53 \% \mathrm{RH}$ and $25^{\circ} \mathrm{C}$ and $W_{\text {Initial }}$ is the initial weight of different formulations after the drying step.

\section{Conclusions}

Poly (vinyl alcohol-co-ethylene) (EVOH) thin systems combined with caffeic acid (CA) at 5 and $15 \mathrm{wt} . \%$, have been realized applying the solvent casting process. Data obtained from optical properties showed transparency of EVOH based films in the visible range stable up to the wavelength value of $350 \mathrm{~nm}$, a slight reduction was registered from 250 to $350 \mathrm{~nm}$ only in the presence of caffeic acid (EVOH_CA films). The presence of caffeic acid influenced the thermal behaviour of EVOH based 
systems; in detail, the thermal degradation stability improved adding CA to the EVOH matrix, while the crystallinity degrees were reduced in active polymeric films. Results from tensile tests showed increased values for strength and deformation at break in EVOH_CA based films. The addition of active ingredient determined a positive radical scavenging activity, confirming the possibility of practically using these polymeric systems in the food packaging sector. EVOH_5CA film represents the best produced formulation. The use of $5 \mathrm{wt} . \%$ of CA represents a strategic amount of active ingredient able to guarantee the structural and functional characteristics.

Author Contributions: Conceptualization, F.L. and D.P.; methodology, F.L. and D.P.; investigation, F.L.; writing-original draft preparation, F.L.; writing-review and editing, D.P. and L.T. All authors have read and agreed to the published version of the manuscript.

Funding: This research received no external funding.

Conflicts of Interest: The authors declare no conflict of interest.

\section{References}

1. Topuz, F.; Uyar, T. Antioxidant, antibacterial and antifungal electrospun nanofibers for food packaging applications. Food Res. Int. 2020, 130, 108927. [CrossRef] [PubMed]

2. Muriel-Galet, V.; Cran, M.J.; Bigger, S.W.; Hernández-Muñoz, P.; Gavara, R. Antioxidant and antimicrobial properties of ethylene vinyl alcohol copolymer films based on the release of oregano essential oil and green tea extract components. J. Food Eng. 2015, 149, 9-16. [CrossRef]

3. Arrieta, M.P.; Peponi, L. Polyurethane based on PLA and PCL incorporated with catechin: Structural, thermal and mechanical characterization. Eur. Polym. J. 2017, 89, 174-184. [CrossRef]

4. Arrieta, M.P.; Sessini, V.; Peponi, L. Biodegradable poly(ester-urethane) incorporated with catechin with shape memory and antioxidant activity for food packaging. Eur. Polym. J. 2017, 94, 111-124. [CrossRef]

5. Arrieta, M.P.; Castro-López, M.a.d.M.; Rayón, E.; Barral-Losada, L.F.; López-Vilariño, J.M.; López, J.; González-Rodríguez, M.V. Plasticized poly (lactic acid)-poly (hydroxybutyrate) (PLA-PHB) blends incorporated with catechin intended for active food-packaging applications. J. Agric. Food Chem. 2014, 62, 10170-10180. [CrossRef]

6. Gómez-Estaca, J.; López-de-Dicastillo, C.; Hernández-Muñoz, P.; Catalá, R.; Gavara, R. Advances in antioxidant active food packaging. Trends Food Sci. Technol. 2014, 35, 42-51. [CrossRef]

7. Wibowo, S.; Buvé, C.; Hendrickx, M.; Van Loey, A.; Grauwet, T. Integrated science-based approach to study quality changes of shelf-stable food products during storage: A proof of concept on orange and mango juices. Trends Food Sci. Technol. 2018, 73, 76-86. [CrossRef]

8. Lagaron, J.M.; Powell, A.K.; Bonner, G. Permeation of water, methanol, fuel and alcohol-containing fuels in high-barrier ethylene-vinyl alcohol copolymer. Polym. Test. 2001, 20, 569-577. [CrossRef]

9. Cabedo, L.; Lagarón, J.M.; Cava, D.; Saura, J.J.; Giménez, E. The effect of ethylene content on the interaction between ethylene-vinyl alcohol copolymers and water-II: Influence of water sorption on the mechanical properties of EVOH copolymers. Polym. Test. 2006, 25, 860-867. [CrossRef]

10. Blanchard, A.; Gouanvé, F.; Espuche, E. Effect of humidity on mechanical, thermal and barrier properties of EVOH films. J. Membr. Sci. 2017, 540, 1-9. [CrossRef]

11. Lagarón, J.M.; Giménez, E.; Gavara, R.; Saura, J.J. Study of the influence of water sorption in pure components and binary blends of high barrier ethylene-vinyl alcohol copolymer and amorphous polyamide and nylon-containing ionomer. Polymer 2001, 42, 9531-9540. [CrossRef]

12. Ju, J.; Chen, X.; Xie, Y.; Yu, H.; Guo, Y.; Cheng, Y.; Qian, H.; Yao, W. Application of essential oil as a sustained release preparation in food packaging. Trends Food Sci. Technol. 2019, 92, 22-32. [CrossRef]

13. Zhang, Y.; Zhou, L.; Zhang, C.; Show, P.L.; Du, A.; Fu, J.; Ashokkumar, V. Preparation and characterization of curdlan/polyvinyl alcohol/ thyme essential oil blending film and its application to chilled meat preservation. Carbohydr. Polym. 2020, 247, 116670. [CrossRef] [PubMed]

14. Felix de Andrade, M.; Diego de Lima Silva, I.; Alves da Silva, G.; David Cavalcante, P.V.; Thayse da Silva, F.; Bastos de Almeida, Y.M.; Vinhas, G.M.; Hecker de Carvalho, L. A study of poly (butylene adipate-co-terephthalate)/orange essential oil films for application in active antimicrobial packaging. LWT 2020, 125, 109148. [CrossRef] 
15. Borzi, F.; Torrieri, E.; Wrona, M.; Nerín, C. Polyamide modified with green tea extract for fresh minced meat active packaging applications. Food Chem. 2019, 300, 125242. [CrossRef]

16. Clifford, M.N. Chlorogenic acids and other cinnamates-nature, occurrence, dietary burden, absorption and metabolism. J. Sci. Food Agric. 2000, 80, 1033-1043. [CrossRef]

17. Magnani, C.; Isaac, V.L.B.; Correa, M.A.; Salgado, H.R.N. Caffeic acid: A review of its potential use in medications and cosmetics. Anal. Methods 2014, 6, 3203-3210. [CrossRef]

18. Sánchez-Moreno, C.; Jiménez-Escrig, A.; Saura-Calixto, F. Study of low-density lipoprotein oxidizability indexes to measure the antioxidant activity of dietary polyphenols. Nutr. Res. 2000, 20, 941-953. [CrossRef]

19. Vinson, J.A.; Teufel, K.; Wu, N. Red wine, dealcoholized red wine, and especially grape juice, inhibit atherosclerosis in a hamster model. Atherosclerosis 2001, 156, 67-72. [CrossRef]

20. Yamada, Y.; Yasui, H.; Sakurai, H. Suppressive Effect of Caffeic Acid and its Derivatives on the Generation of UVA-induced Reactive Oxygen Species in the Skin of Hairless Mice and Pharmacokinetic Analysis on Organ Distribution of Caffeic Acid in ddY Mice. Photochem. Photobiol. 2006, 82, 1668-1676. [CrossRef]

21. Murray, J.C.; Burch, J.A.; Streilein, R.D.; Iannacchione, M.A.; Hall, R.P.; Pinnell, S.R. A topical antioxidant solution containing vitamins $C$ and $E$ stabilized by ferulic acid provides protection for human skin against damage caused by ultraviolet irradiation. J. Am. Acad. Dermatol. 2008, 59, 418-425. [CrossRef] [PubMed]

22. Luzi, F.; Puglia, D.; Dominici, F.; Fortunati, E.; Giovanale, G.; Balestra, G.M.; Torre, L. Effect of gallic acid and umbelliferone on thermal, mechanical, antioxidant and antimicrobial properties of poly (vinyl alcohol-co-ethylene) films. Polym. Degrad. Stab. 2018, 152, 162-176. [CrossRef]

23. Iglesias Montes, M.L.; Luzi, F.; Dominici, F.; Torre, L.; Cyras, V.P.; Manfredi, L.B.; Puglia, D. Design and characterization of PLA bilayer films containing lignin and cellulose nanostructures in combination with umbelliferone as active ingredient. Front. Chem. 2019, 7, 157. [CrossRef] [PubMed]

24. Luzi, F.; Pannucci, E.; Santi, L.; Kenny, J.M.; Torre, L.; Bernini, R.; Puglia, D. Gallic Acid and Quercetin as Intelligent and Active Ingredients in Poly (vinyl alcohol) Films for Food Packaging. Polymers 2019, 11, 1999. [CrossRef] [PubMed]

25. Luzi, F.; Fortunati, E.; Di Michele, A.; Pannucci, E.; Botticella, E.; Santi, L.; Kenny, J.M.; Torre, L.; Bernini, R. Nanostructured starch combined with hydroxytyrosol in poly (vinyl alcohol) based ternary films as active packaging system. Carbohydr. Polym. 2018, 193, 239-248. [CrossRef]

26. Fortunati, E.; Luzi, F.; Dugo, L.; Fanali, C.; Tripodo, G.; Santi, L.; Kenny, J.M.; Torre, L.; Bernini, R. Effect of hydroxytyrosol methyl carbonate on the thermal, migration and antioxidant properties of PVA-based films for active food packaging. Polym. Int. 2016, 65, 872-882. [CrossRef]

27. Liu, J.; Wang, X.; Bai, R.; Zhang, N.; Kan, J.; Jin, C. Synthesis, characterization, and antioxidant activity of caffeic-acid-grafted corn starch. Starch - Stärke 2018, 70, 1700141. [CrossRef]

28. Fortunati, E.; Luzi, F.; Fanali, C.; Dugo, L.; Belluomo, M.G.; Torre, L.; Kenny, J.M.; Santi, L.; Bernini, R. Hydroxytyrosol as Active Ingredient in Poly (vinyl alcohol) Films for Food Packaging Applications. J. Renew. Mater. 2017, 5, 81-95. [CrossRef]

29. Santos, N.A.; Cordeiro, A.M.T.M.; Damasceno, S.S.; Aguiar, R.T.; Rosenhaim, R.; Carvalho Filho, J.R.; Santos, I.M.G.; Maia, A.S.; Souza, A.G. Commercial antioxidants and thermal stability evaluations. Fuel 2012, 97, 638-643. [CrossRef]

30. Kumar, N.; Pruthi, V.; Goel, N. Structural, thermal and quantum chemical studies of p-coumaric and caffeic acids. J. Mol. Struct. 2015, 1085, 242-248. [CrossRef]

31. Baykal, A.; Amir, M.; Günerb, S.; Sözeri, H. Preparation and characterization of SPION functionalized via caffeic acid. J. Magn. Magn. Mater. 2015, 395, 199-204. [CrossRef]

32. Alevizou, E.I.; Voutsas, E.C. Solubilities of p-coumaric and caffeic acid in ionic liquids and organic solvents. J. Chem. Thermodyn. 2013, 62, 69-78. [CrossRef]

33. Luzi, F.; Di Michele, A.; Torre, L.; Puglia, D. Active Role of ZnO Nanorods in thermomechanical and barrier performance of Poly (vinyl alcohol-co-ethylene) formulations for flexible packaging. Polymers 2019, 11, 922. [CrossRef]

34. Wang, Y.; Pitto-Barry, A.; Habtemariam, A.; Romero-Canelon, I.; Sadler, P.J.; Barry, N.P.E. Nanoparticles of chitosan conjugated to organo-ruthenium complexes. Inorg. Chem. Front. 2016, 3, 1058-1064. [CrossRef]

35. Cornard, J.-P.; Caudron, A.; Merlin, J.-C. UV-visible and synchronous fluorescence spectroscopic investigations of the complexation of $\mathrm{Al}$ (III) with caffeic acid, in aqueous low acidic medium. Polyhedron 2006, 25, 2215-2222. [CrossRef] 
36. Nakamura, K.; Shirato, M.; Kanno, T.; Lingström, P.; Örtengren, U.; Niwano, Y. Photo-irradiated caffeic acid exhibits antimicrobial activity against Streptococcus mutans biofilms via hydroxyl radical formation. Sci. Rep. 2017, 7, 1-13. [CrossRef]

37. López-de-Dicastillo, C.; Alonso, J.M.; Catalá, R.; Gavara, R.; Hernández-Muñoz, P. Improving the Antioxidant Protection of Packaged Food by Incorporating Natural Flavonoids into Ethylene - Vinyl Alcohol Copolymer (EVOH) Films. J. Agric. Food Chem. 2010, 58, 10958-10964. [CrossRef]

38. Araghi, M.; Moslehi, Z.; Mohammadi Nafchi, A.; Mostahsan, A.; Salamat, N.; Daraei Garmakhany, A. Cold water fish gelatin modification by a natural phenolic cross-linker (ferulic acid and caffeic acid). Food Sci. Nutr. 2015, 3, 370-375. [CrossRef]

39. Sadeghi, K.; Shahedi, M. Physical, mechanical, and antimicrobial properties of ethylene vinyl alcohol copolymer/chitosan/nano-ZnO (ECNZn) nanocomposite films incorporating glycerol plasticizer. J. Food Meas. Charact. 2016, 10, 137-147. [CrossRef]

40. López-de-Dicastillo, C.; Gómez-Estaca, J.; Catalá, R.; Gavara, R.; Hernández-Muñoz, P. Active antioxidant packaging films: Development and effect on lipid stability of brined sardines. Food Chem. 2012, 131, 1376-1384. [CrossRef]

41. López de Dicastillo, C.; Nerín, C.; Alfaro, P.; Catalá, R.; Gavara, R.; Hernández-Muñoz, P. Development of New Antioxidant Active Packaging Films Based on Ethylene Vinyl Alcohol Copolymer (EVOH) and Green Tea Extract. J. Agric. Food Chem. 2011, 59, 7832-7840. [CrossRef] [PubMed]

42. Alvarez, V.A.; Ruseckaite, R.A.; Vázquez, A. Kinetic analysis of thermal degradation in poly (ethylene-vinyl alcohol) copolymers. J. Appl. Polym. Sci. 2003, 90, 3157-3163. [CrossRef]

43. Vannini, M.; Marchese, P.; Celli, A.; Lorenzetti, C. Strategy to modify the crystallization behavior of EVOH32 through interactions with low-molecular-weight molecules. Ind. Eng. Chem. Res. 2016, 55, 3517-3524. [CrossRef]

44. Murthy, P.S.; Naidu, M.M. Recovery of Phenolic Antioxidants and Functional Compounds from Coffee Industry By-Products. Food Bioprocess. Technol. 2012, 5, 897-903. [CrossRef]

45. Gülçin, İ. Antioxidant activity of caffeic acid (3,4-dihydroxycinnamic acid). Toxicology 2006, 217, $213-220$. [CrossRef]

46. Pastor, C.; Sánchez-González, L.; Cháfer, M.; Chiralt, A.; González-Martínez, C. Physical and antifungal properties of hydroxypropylmethylcellulose based films containing propolis as affected by moisture content. Carbohydr. Polym. 2010, 82, 1174-1183. [CrossRef]

47. Cano, A.; Fortunati, E.; Cháfer, M.; Kenny, J.M.; Chiralt, A.; González-Martínez, C. Properties and ageing behaviour of pea starch films as affected by blend with poly (vinyl alcohol). Food Hydrocoll. 2015, 48, 84-93. [CrossRef]

48. Fortunati, E.; Benincasa, P.; Balestra, G.M.; Luzi, F.; Mazzaglia, A.; Del Buono, D.; Puglia, D.; Torre, L. Revalorization of barley straw and husk as precursors for cellulose nanocrystals extraction and their effect on PVA_CH nanocomposites. Ind. Crop. Prod. 2016, 92, 201-217. [CrossRef]

49. Martínez-Abad, A.; Lagaron, J.M.; Ocio, M.J. Development and Characterization of Silver-Based Antimicrobial Ethylene-Vinyl Alcohol Copolymer (EVOH) Films for Food-Packaging Applications. J. Agric. Food Chem. 2012, 60, 5350-5359. [CrossRef]

50. Faisant, J.B.; Aït-Kadi, A.; Bousmina, M.; Desche^nes, L. Morphology, thermomechanical and barrier properties of polypropylene-ethylene vinyl alcohol blends. Polymer 1998, 39, 533-545. [CrossRef]

51. Roohani, M.; Habibi, Y.; Belgacem, N.M.; Ebrahim, G.; Karimi, A.N.; Dufresne, A. Cellulose whiskers reinforced polyvinyl alcohol copolymers nanocomposites. Eur. Polym. J. 2008, 44, 2489-2498. [CrossRef]

52. Byun, Y.; Kim, Y.T.; Whiteside, S. Characterization of an antioxidant polylactic acid (PLA) film prepared with $\alpha$-tocopherol, BHT and polyethylene glycol using film cast extruder. J. Food Eng. 2010, 100, 239-244. [CrossRef]

Sample Availability: Not available.

(C) 2020 by the authors. Licensee MDPI, Basel, Switzerland. This article is an open access article distributed under the terms and conditions of the Creative Commons Attribution (CC BY) license (http://creativecommons.org/licenses/by/4.0/). 